\title{
XRCC1 Gene Polymorphism, Diet and Risk of Colorectal Cancer in Thailand
}

\author{
Kirati Poomphakwaen ${ }^{1}$, Supannee Promthet ${ }^{1 *}$, Krittika Suwanrungruang ${ }^{2}$, \\ Peechanika Chopjitt ${ }^{3}$, Nopparat Songserm ${ }^{4}$, Surapon Wiangnon ${ }^{5}$
}

\begin{abstract}
Background: Colorectal cancer (CRC) is one of the most common cancers worldwide. This study aimed to investigate the interaction between the presence of a polymorphism of the $X R C C 1$ gene and known risk factors for colorectal cancer in Thailand. Materials and Methods: A hospital-based case-control study was conducted in Thailand. The participants were 230 histologically confirmed new cases and 230 controls matched by sex and age and recruited from the same hospital. Information about demographic characteristics, life style, and dietary habits was collected using structured interviews, and blood samples were taken which were used for the detection of a homozygous and heterozygous polymorphisms of $\mathrm{XRCC1}$. Associations were assessed using multiple conditional logistic regression. Results: In the univariate analysis, factors found to be significantly associated with an increased risk for CRC were the presence of the XRCC1 AA homozygote (OR= 4.95; 95\% CI: 1.99-12.3), a first degree family history of cancer $(\mathrm{OR}=1.74 ; 95 \% \mathrm{CI}$ : 1.18-2.58), and a high frequency of pork consumption $(\mathrm{OR}=1.49 ; 95 \% \mathrm{CI}$ : 1.00-2.21). Intakes of fish fruit and vegetables appeared to be protective factors, but the associations were not statistically significant. In the multivariate analysis only the XRCC1 AA homozygote polymorphism and a family history of cancer emerged as risk factors $(\mathrm{OR}=\mathbf{4 . 9 6}$; 95\% CI: 1.90 12.95 and $\mathrm{OR}=1.80 ; 95 \%$ CI: 1.18-2.72, respectively). Conclusions: While the XRCC1 AA homozygote and a family history of cancer were found to be associated with an increased risk of CRC, none of the dietary intake variables were clearly identified as risk or protective factors. There is a need for further research to determine the reasons for this.
\end{abstract}

Keywords: XRCC1 polymorphism - risk factors - colorectal cancer - Thailand

Asian Pac J Cancer Prev, 15 (17), 7479-7486

\section{Introduction}

Globally, colorectal cancer (CRC) is the third most common cancer in males and the second most common cancer in females, and it ranks as the fourth most frequent cause of cancer death in males and the third in females (Ferlay et al., 2013). There has been a remarkable decrease of the CRC rate in Western countries, but it seems to be increasing in some countries in Asia (Sung et al., 2005; Yee et al., 2009), also in Thailand (Ferlay et al., 2013). The incidence of CRC in Thailand now ranks the disease as the third most common cancer in males and the fifth in females (Ferlay et al., 2013). It is known that CRC is related to dietary habits, especially those associated with a Western lifestyle (De Stefani et al., 2011; De Stefani et al., 2012; Durko and Malecka-Panas, 2014).

People around the world, including those living in Asian countries, appear to be increasingly following a pattern of Western food consumption practices, which are associated with a growing incidence of chronic diseases and colorectal cancer, and this also appears to be happening in Thailand. Particular food cultures or dietary patterns may increase the risk of developing colorectal cancer (Navarro, 2005; Randi et al., 2010; Makambi et al., 2011; Magalhaes et al., 2012).

CRC is a complex disease, which results from both genetic and environmental factors (Wang et al., 2010). It is estimated that $65-85 \%$ of cases are sporadic, and the rest are hereditary and familial (Kabzinski et al., 2010). Dietary risk factors for CRC in a Thai population have been explored in previous studies. Sriamporn et al. (2007) reported that red meat (beef and/or pork) was a risk factor for colorectal cancer; alcohol was also a risk factor, but only in the univariate analysis. In a subsequent study of colon cancer (Promthet et al., 2010), the roles of beef and pork were investigated separately, and neither emerged as a risk factor; alcohol was a risk factor, but only at the lower level of consumption. For rectal cancer (Promthet et al., 2012), pork, but not beef, was a risk factor, and there was no association with alcohol.

${ }^{1}$ Department of Epidemiology, Faculty of Public Health, ${ }^{2}$ Cancer Unit, Faculty of Medicine, ${ }^{3}$ Department of Microbiology, ${ }^{5}$ Department of Paediatrics, Faculty of Medicine, Khon Kaen University, Khon Kaen, ${ }^{4}$ Department of Community Health, Faculty of Public Health, Ubon Ratchathani Rajabhat University, Thailand*For correspondence: supannee@kku.ac.th 
The roles of both genetic and environmental factors as risk factors for CRC are in need of further study. Humans are routinely exposed to mutagenic and carcinogenic chemicals via smoking, over-cooked food and other sources, all of which can lead to DNA damage when DNA adducts occur and lead to carcinogenesis (Wang et al., 2010). However, DNA damage can be reversed by DNA repair pathways. Unfortunately, deficiencies in DNA repair have been associated with an individual susceptibility to cancer, and polymorphisms of DNA repair genes may lead to the increased risk of CRC. The X-ray repair cross-complementing group 1(XRCC1) gene was initially discovered through its role in repairing DNA damage caused by ionizing radiation and plays an important role in base excision repair (BER) and single-strand break repair processes (Khan et al., 2013; Nissar et al., 2013), and $X R C C 1$ polymorphisms have been studied as potentially connected with susceptibility to the occurrence of various cancers (Kabzinski et al., 2010).

Three coding polymorphisms of the DNA repair gene XRCC1 have been identified in humans (Arg 194Trp, Arg280His, and Arg399Gln). XRCC1 gene codon 399 (exon 10, base G to A, amino acid Arg to Gln, dbSNP no. rs25487) is a common and non-conservative amino acid which may alter XRCC1 function (Yi et al., 2013). Despite the fact that polymorphisms of the XRCC1 have been widely examined and relate to several types of cancers (Zhao et al., 2012; Yi et al., 2013), their roles in CRC in a Thai population have not been established.

The aim of this case-control study was to investigate the associations of the XRCC1 DNA repair gene and its polymorphisms with the risk of CRC in a Thai population and to explore ways in which any of these associations are modified by various potential environmental factors.

\section{Materials and Methods}

\section{Subjects and data collection}

This was a hospital-based case-control study, in which 230 new cases of colorectal cancer were recruited between October, 2002, and October, 2006, from Srinagarind Hospital, the main teaching facility of the Faculty of Medicine, Khon Kaen University, and from the Regional Hospital of Khon Kaen Province. Each case was matched with one control by gender, age ( \pm 3years) and province of residence. All of cases were from Khon Kaen Province or neighboring provinces. The diagnosis of colorectal cancer was confirmed histologically in all cases. The controls were hospital patients suffering from a variety of disorders such as inflammation and diseases of the eyes or genitourinary system, and all patients with any form of cancer or any disorder of the digestive system were excluded. All participants gave their informed consent for inclusion in the study.

The research project was approved by the Khon Kaen University Ethics Committee for Human Research (reference no. HE561328 dated September 9, 2013), and this was based on the Declaration of Helsinki and the Good Clinical Practice Guidelines of the International Conference on Harmonisation.

Each participant was interviewed by one of two trained interviewers using a structured questionnaire, which was in two sections. The first section was composed of items related to demographic variables and socioeconomic status, history of illnesses, history of cancer in first degree relatives, and smoking habits.

The second part was essentially a semi-quantitative food and beverage intake frequency questionnaire. There were nine food item categories, and each item was designed to elicit information about frequency of consumption (daily, weekly, monthly, and less than once a month). Beverage items covered the consumption of alcoholic drinks and coffee. For each type of alcoholic drink questions were asked about whether or not the participant consumed the beverage, the frequency of drinking it, and the amount consumed per occasion. For coffee, the participants were simply classified as drinkers or non-drinkers.

For the analysis of cigarette smoking, the participants were categorized as smokers or non-smokers. Smokers were defined as those who had smoked at least one type of cigarette per day for six months. An average number of cigarettes per year was computed on the basis of all smoking periods reported, and participants were then dichotomized into 'low' and 'high' smokers using the median number smoked per year by the controls. In calculating the average number of cigarettes smoked annually, no distinction was made between filter and nonfilter cigarettes, but a correction factor of 1.5 was used where subjects had smoked the longer Yamuan homemade cheroot (annual filtered/non-filtered cigarettes plus 1.5 annual number Yamuan smoked).

Alcohol beverage drinking was categorised into two groups: drinkers were defined as those who consumed at least one type of alcohol beverage (beer, Thai rice wine or Sato and white or red whiskey and whiskey) at least once a month, and those who did not meet this criterion were categorized as non-drinkers. The level of alcohol consumption of each drinker was calculated in terms of alcohol units with a unit of alcohol defined as 10 milliliters (or approximately 8 grams) of ethyl alcohol. The number of units of alcohol in a drink was determined by multiplying volume of the drink (in milliliters) by its alcohol percentage and dividing by 1,000. The average daily amount of alcohol consumed was measured in terms of grams of per day with the units of alcohol content (\% alc/vol) based on $5.0 \%$ for beer, $7.0 \%$ for Sato, $40 \%$ for white whiskey, and $35 \%$ for red whiskey. The averages were calculated and converted into units of alcohol per day. The participants were able to be further categorized as non-drinkers and drinkers of $\leq 0.5$ units per day or $>0.5$ units per day.

The levels of dietary intake of total vegetables, total fruits, fish, beef, pork, and poultry were measured on the basis of frequency of daily consumption in the previous year, and participants were categorized as low or high consumers of these items using the median daily consumption in the controls.

The levels of intake of vegetable oil, pork oil, and coconut milk were categorised on the basis of frequency of consumption: never, sometimes, and always. The degree of spiciness of foods (non- or a little spicy, medium, and 
very spicy) was determined according to the judgment of the individual participants.

\section{Laboratory methods}

Specimen collection and DNA extraction, blood samples (buffy coat fractions) of the cases and their matched controls were extracted for genomic DNA analysis using a standard technique at the Nagoya City University Medical School, Nagoya, Japan. Buffy coat fractions were available for 230 (100\%) of the eligible colorectal cancer cases and were available for 230 matched-controls. Genomic DNA was extracted from buffy coat fractions using the standard protocol of Genomic DNA Mini Kit with Proteinase K (Geneaid Biotech).

PCR amplification and genetic polymorphisms detection PCR amplification and polymorphism detection were performed in the Microbiology Laboratory at the Faculty of Medicine, Khon Kaen University, Thailand. The realtime polymerase chain reactions with high resolution melting analysis (Real-time PCR-HRM) technique for the $X R C C 1$ polymorphism were performed in a 96-well plate in the LightCycler ${ }^{\circledR} 480$ Real-time PCR system. Of those with DNA samples, genotyping was successfully carried out for $95 \%$ (484 out of 508) of all samples for XRCC1.

The amplification of XRCC1 G399A used two primers; [F]: 5'-AGT GGG TGC TGG ACT GTC-3' and [R]: 5'-TTG CCC AGC ACA GGA TAA-3', HRM data were analyzed using the LightCycler $480 \AA$ Gene Scaning Softwere version 1.5 (Roche). Normalized and temperature-shifted melting curves carrying a sequence variation were evaluated and compared with the widetype sample. Sequence variations were distinguished by the different shapes of melting curves for each genotype. Melting peaks of sequence variation were analyzed and compared with the wild-type sample. Different plots were distinguished by different melting peaks for each genotype. To improve the genotyping quality and validation, genotyping of $10 \%$ of random samples was confirmed by the PCR with the restriction fragment length polymorphism technique (PCR-RFLP).

\section{Statistical analysis}

The observed number of each genotype was compared with the expected values based on the Hardy-Weinberg principle. The differences between the frequency of occurrence of the alleles and genotypes in the groups were analysed by a $\chi^{2}$-test. The associations between colorectal cancer and potential risk factors were assessed using odds ratios (ORs) with a $95 \%$ confidence interval (95\% CI) derived from a conditional logistic regression and McNemar's test. In the univariate analysis, crude ORs were computed for each independent variable. Those exposure variables found to be significantly (p-value $<0.25$ ) associated with colorectal cancer in the univariate analysis and those with no significant association in the present analysis, but which were found to have statistically significant associations in the reviewed literature, were included together in a multiple conditional logistic regression analysis with backward elimination.
All analyses were conducted using STATA (Version 10.0). Except for the process of selecting variables to be included in the multivariate analysis, statistical significance was set as $\mathrm{p}<0.05$.

\section{Results}

Table 1 shows the distribution of the general characteristics of cases and controls. Most of the participants were male, aged 45 years or more, did not attend school beyond primary level, and were employed as farmers or agricultural workers. Similar distributions for cases and controls were found on the unmatched variables.

The results of the univariate analyses for the genetic and dietary variables are shown in Table 2 . The prevalence of the A allele of the XRCC1 G399A polymorphism among the case and control groups was exactly the same (45\%). The XRCC1 GA heterozygous genotype appeared to be a risk factor for CRC when compared with the GG wild-type, but was not statistically significant $(\mathrm{OR}=1.29$; 95\%CI: 0.89-1.89). However, the XRCC1 AA homozygote was significantly associated with an increased risk of CRC (OR=4.95; 95\%CI: 1.99-12.3). While a statistically significant increased risk was also associated with a family history of cancer (OR=1.74; 95\%CI: 1.18-2.58), the apparently increased risks related to smoking, alcohol consumption, and drinking of coffee were not statistically significant. Regarding dietary intakes, a high frequency of pork consumption was found to have a statistically significant association with an elevated risk of CRC $(\mathrm{OR}=1.49$; 95\%CI: 1.00-2.21), but the increased risks associated with high frequencies of eating beef and poultry were not statistically significant $(\mathrm{OR}=1.20$; 95\%CI: 0.81 1.77 , and $\mathrm{OR}=1.45 ; 95 \% \mathrm{CI}: 0.98-2.15$, respectively). High frequencies of eating fish, fruits, and vegetables appeared to be protective factors for CRC, but were not statistically significant.

Table 3 shows the results of gene-environment interaction of the XRCC1 gene polymorphisms. A

Table 1. Characteristics of Colorectal Cancer Cases and Controls

\begin{tabular}{llrrrr}
\hline Variables & & \multicolumn{2}{c}{ Cases } & \multicolumn{2}{c}{ Controls } \\
& & $\mathrm{n}=230$ & $\%$ & $\mathrm{n}=230$ & $\%$ \\
\hline Sex & Male & 125 & 54.4 & 125 & 54.4 \\
\multirow{4}{*}{ Age (years) } & Female & 105 & 45.6 & 105 & 45.6 \\
& $<45$ & 55 & 23.9 & 55 & 23.9 \\
& $45-55$ & 64 & 27.8 & 65 & 28.2 \\
& 56-65 & 72 & 31.3 & 71 & 30.9 \\
& $>65$ & 39 & 17 & 39 & 17 \\
Marital status & Mean (SD) & 54 & $(11.3)$ & 53.9 & $(11.4)$ \\
& Single & 7 & 3 & 17 & 7.4 \\
& Married & 187 & 81.7 & 169 & 73.8 \\
& Separated, widowed & 35 & 15.3 & 43 & 18.8 \\
& Agriculture, farmer & 154 & 67.5 & 153 & 67.4 \\
& Office, technical work & 21 & 9.2 & 22 & 9.7 \\
& Professional work & 25 & 11 & 28 & 12.3 \\
& Others & 28 & 12.3 & 24 & 10.6 \\
Education & $\leq$ Primary school & 175 & 76.4 & 185 & 80.8 \\
& $\geq$ Secondary school & 54 & 23.6 & 44 & 19.2 \\
& GG & 102 & 44.4 & 126 & 54.8 \\
& GA & 101 & 43.9 & 97 & 42.2 \\
& AA & 27 & 11.7 & 7 & 3 \\
& GA or AA (any A allele) & 128 & 55.7 & 104 & 45 \\
\hline
\end{tabular}

Asian Pacific Journal of Cancer Prevention, Vol 15, 2014 
Kirati Poomphakwaen et al

statistically significant association was found between the risk of $\mathrm{CRC}$ and the presence of both a family history of cancer and the XRCC1 GA heterozygous genotype $(\mathrm{OR}=2.23$; 95\%CI: 1.12-4.13). Statistically significant associations were also found in those who had XRCC1 GA heterozygous genotype combined with a low alcohol intake ( $\leq 0.5$ unit per day) or a high frequency of pork

Table 2. Univariate Analyses of Environmental and Dietary Variables

\begin{tabular}{|c|c|c|c|c|c|c|c|c|c|c|c|c|}
\hline $\begin{array}{l}\text { of cancer and } \\
(\mathrm{OR}=2.23 ; 95\end{array}$ & CI: & $: 1.12$ & 4.13 & 3). $\mathrm{S}$ & tistically sign & iificant & & Variables & $\begin{array}{c}\text { Case } \\
\text { n }(\%)\end{array}$ & $\begin{array}{l}\text { Control } \\
\mathrm{n} \quad(\%)\end{array}$ & OR $(95 \% \mathrm{CI})$ & $\overline{\mathrm{p} \text {-value }}$ \\
\hline associations & 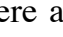 & SO & ( & 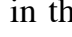 & Se wilo mad $\lambda$ & Cl & $X R C C 1$ & Family history & of cancer & & & 0.0006 \\
\hline GA heterozyg & $s g$ & enoty & $\mathrm{eco}$ & $\mathrm{mbi}$ & ed with a low a & alcohol & GG & No & $65(28.3)$ & $93(40.6)$ & 1 & \\
\hline intake $(<05$ & & & & & & & & Yes & $37(16.1)$ & $32(14)$ & $1.54(0.88-2.68)$ & 0.129 \\
\hline intake $(\leq 0$ & & & & & & & GA & No & $63(27.4)$ & $74(32.3)$ & $1.19(0.76-1.86)$ & 0.45 \\
\hline & & & & & & & & Yes & $38(16.5)$ & $23(10)$ & $2.23(1.12-4.13)$ & 0.011 \\
\hline & & & & & & & AA & No & $16(6.9)$ & $5(2.2)$ & $4.59(1.57-13.39)$ & 0.005 \\
\hline & & & & & & & & Yes & $11(4.8)$ & $2(0.9)$ & $7.46(1.57-35.57)$ & 0.012 \\
\hline & & & & & & & $X R C C 1$ & Smoking & & & & 0.006 \\
\hline Dietary & & & & & & & GG & Nonsmoker & $59(25.7)$ & $77(33.5)$ & 1 & \\
\hline Variables & & ases & Con & trols & OR $(95 \% \mathrm{CI})$ & p-value & & Smoker & 43 (18.7) & $49(21.3)$ & $1.46(0.65-3.28)$ & 0.352 \\
\hline & $\Pi$ & $\%$ & $\mathrm{n}$ & $\%$ & & & GA & $\begin{array}{l}\text { Nonsmoker } \\
\text { Smoker }\end{array}$ & $\begin{array}{l}53(23) \\
48(20.9)\end{array}$ & $\begin{array}{l}51(22.2) \\
46(20)\end{array}$ & $\begin{array}{l}1.43(0.84-2.43) \\
1.63(0.77-3.46)\end{array}$ & $\begin{array}{l}0.186 \\
0.205\end{array}$ \\
\hline & & & & & & & AA & Nonsmoker & $12(5.2)$ & $3(1.3)$ & $4.89(1.32-18.04)$ & 0.017 \\
\hline RCC1 G399A & & & & & & & & Smoker & $15(6.5)$ & $4(1.7)$ & $6.95(1.71-28.16)$ & 0.007 \\
\hline GG & 102 & 44.4 & 126 & 54.8 & 1 & 0.0005 & $X R C C 1$ & Average no. of & cigarettes $\mathrm{pe}$ & er year & & 0.016 \\
\hline GA & 101 & 43.9 & 97 & 42.2 & $1.29(0.89-1.89)$ & & GG & Nonsmoker & $59(25.6)$ & $77(33.5)$ & 1 & \\
\hline AA & 27 & 11.7 & 7 & 3 & $4.95(1.99-12.3)$ & & & Low & $32(13.9)$ & $37(16.1)$ & $1.48(0.63-3.49)$ & 0.367 \\
\hline Family history of $\mathrm{c}$ & cancer & & & & & & & High & $11(4.8)$ & $12(5.2)$ & $1.43(0.51-4.0)$ & 0.493 \\
\hline No & 144 & 62.6 & 172 & 75.1 & 1 & 0.005 & GA & Nonsmoker & $53(23)$ & $51(22.2)$ & $1.45(0.85-2.47)$ & 0.171 \\
\hline Yes & 86 & 37.4 & 57 & 24.9 & 1.74 & & & Low & $33(14.4)$ & 29 (12.6) & $1.82(0.8-4.16)$ & 0.154 \\
\hline Smoki & 00 & 51.4 & & & $1.74(1.10-2.00)$ & & & High & $15(6.5)$ & $17(7.4)$ & $1.36(0.54-3.41)$ & 0.511 \\
\hline $\mathrm{Sm}$ & & & & & & & AA & Nonsmoker & $12(5.2)$ & $3(1.3)$ & $4.93(1.33-18.2)$ & 0.017 \\
\hline Nonsmoker & 124 & 53.9 & 131 & 57 & 1 & 0.235 & & Low & $10(4.4)$ & $1(0.4)$ & $16.99(1.9-148.7)$ & 0.011 \\
\hline Smoker & 106 & 46.1 & 99 & 43 & $1.5(0.76-2.95)$ & & & High & $5(2.2)$ & $3(1.3)$ & $3.22(0.59-17.4)$ & 0.175 \\
\hline Average no. of cig & arettes & es per ye & & & & & $X R C C 1$ & Alcohol drinkiı & & & & 0.008 \\
\hline Nonsmoker & 124 & 53.9 & 131 & 57 & 1 & 0.418 & GG & Nondrinker & $59(25.6)$ & $70(30.4)$ & 1 & \\
\hline Low (36-5475) & 75 & 32.6 & 67 & 29.1 & $1.61(0.78-3.31)$ & & & Drinker & $43(18.7)$ & $56(24.4)$ & $1.03(0.55-1.89)$ & 0.936 \\
\hline High $(>5475)$ & 31 & 13.5 & 32 & 13.9 & $1.35(0.63-2.9)$ & & GA & Nondrinker & $49(21.3)$ & $49(21.3)$ & $1.23(0.71-2.14)$ & 0.467 \\
\hline & & & & & & & & Drinker & $52(22.6)$ & 48 (20.9) & $1.38(0.76-2.53)$ & 0.293 \\
\hline Alconol drinking & & & & & & & AA & Nondrinker & $10(4.4)$ & $3(1.3)$ & $3.87(1.02-14.73)$ & 0.047 \\
\hline Nondrinker & 118 & 51.3 & 122 & 53 & 1 & 0.628 & & Drinker & $17(7.4)$ & $4(1.7)$ & $6.15(1.65-22.96)$ & 0.007 \\
\hline Drinker & 112 & 48.7 & 108 & 47 & $1.13(0.70-1.81)$ & & $X R C C 1$ & Units of alcoho & ol per day & & & 0.002 \\
\hline Units of alcohol pe & er day & & & & & & GG & Nondrinker/< & $<1$ per month & & & \\
\hline Nondrinker/<1p & er mo & onth & & & & & & & $65(28.3)$ & $85(36.9)$ & 1 & \\
\hline & 134 & 58.3 & 153 & 66.5 & 1 & & & $\leq 0.50$ & $13(5.7)$ & $16(7)$ & $1.32(0.55-3.14)$ & 0.533 \\
\hline$\leq 0.50$ & 36 & 15.6 & 27 & 11.8 & $1.71(0.95-3.11)$ & & & $>0.50$ & $24(10.4)$ & $25(10.9)$ & $1.57(0.77-3.22)$ & 0.216 \\
\hline$>0.50$ & 60 & 261 & 50 & 217 & 156 & & GA & Nondrinker/ $<$ & $<1$ per month & & & \\
\hline Coffee & & & 30 & & $1.50(0.94-2.57)$ & & & & $59(25.7)$ & $65(28.3)$ & $1.21(0.73-2.01)$ & 0.455 \\
\hline Coffee & & & & & & & & $\leq 0.50$ & $18(7.8)$ & $8(3.5)$ & $3.72(1.43-9.69)$ & 0.007 \\
\hline No & 157 & 68.3 & 169 & 73.5 & 1 & 0.205 & & $>0.50$ & $24(10.4)$ & $24(10.4)$ & $1.45(0.73-2.89)$ & 0.29 \\
\hline Yes & 73 & 31.7 & 61 & 26.5 & $1.31(0.86-1.98)$ & & AA & Nondrinker/< & $<1$ per month & & & \\
\hline Beef (average time & s/day & & & & & & & & $10(4.3)$ & $3(1.3)$ & $4.28(1.11-16.56)$ & 0.035 \\
\hline Low $(\leq 0.03)$ & 123 & 53.5 & 132 & 57.4 & 1 & 0.37 & & $\leq 0.50$ & $5(2.2)$ & $3(1.3)$ & $2.49(0.44-14.13)$ & 0.302 \\
\hline High $(>0.03)$ & 107 & 46.5 & 98 & 42.6 & $1.20(0.81-1.77)$ & & & $>0.50$ & $12(5.2)$ & $1(0.4)$ & $20.58(2.48-170.4)$ & 0.005 \\
\hline Pork (average time & s/day & & & & & & $X R C C 1$ & Coffee & & & 0.002 & \\
\hline Low $(\leq 0.5)$ & 146 & 64.3 & 168 & 73 & 1 & 047 & GG & No & $70(30.5)$ & 94 (40.9) & 1 & \\
\hline $\operatorname{High}(>0.5)$ & 81 & 357 & 62 & 27 & $149(100-221)$ & 047 & & Yes & $32(14)$ & $32(13.9)$ & $1.47(0.79-2.72)$ & 0.219 \\
\hline & & 50.1 & 62 & 21 & $1.49(1.00-2.21)$ & & GA & No & $73(31.9)$ & $70(30.4)$ & $1.44(0.91-2.29)$ & 0.122 \\
\hline Poultry (average ti & $\mathrm{mes} / \mathrm{d}$ & day) & & & & & & Yes & $27(11.8)$ & 27 (11.7) & $1.34(0.72-2.49)$ & 0.351 \\
\hline Low $(\leq 0.2)$ & 149 & 64.8 & 168 & 73 & 1 & 0.06 & AA & No & $13(5.7)$ & $5(2.2)$ & $3.32(1.14-9.72)$ & 0.028 \\
\hline High $(>0.2)$ & 81 & 35.2 & 62 & 27 & $1.45(0.98-2.15)$ & & & Yes & $14(6.1)$ & $2(0.9)$ & $16.99(2.16-133.6)$ & 0.007 \\
\hline Fish (average time & s/day) & & & & & & $X R C C 1$ & Beef (average $t$ & times/day) & & & 0.002 \\
\hline Low $(<2)$ & 212 & & & & 1 & 862 & GG & Low & $54(23.5)$ & $70(30.4)$ & 1 & \\
\hline & 212 & 92.2 & 211 & 91.1 & 1 & 52 & & High & $48(20.9)$ & $56(24.4)$ & $1.19(0.68-2.09)$ & 0.533 \\
\hline High $(\geq 2)$ & 18 & 7.8 & 19 & 8.3 & $0.94(0.78-1.86)$ & & GA & Low & $54(23.5)$ & $56(24.4)$ & $1.29(0.76-2.21$ & 0.349 \\
\hline Vegetables (averag & e time & hes/day) & & & & & & High & $47(20.4)$ & $41(17.8)$ & $1.55(0.88-2.73)$ & 0.131 \\
\hline Low $(<2.5)$ & 129 & 56.1 & 126 & 54.8 & 1 & 0.753 & AA & Low & $15(6.5)$ & $6(2.6)$ & $3.58(1.25-10.3)$ & 0.018 \\
\hline High $(\geq 2.5)$ & 101 & 43.9 & 104 & 45.2 & $0.94(0.62-1.41)$ & & & High & $12(5.2)$ & $1(0.4)$ & $17.0(2.1-137.4)$ & 0.008 \\
\hline Fruits (average tim & es/da & & & & & & XRCCI & Pork (average $\mathrm{t}$ & times/day) & & & 0.002 \\
\hline Low $(<0.6)$ & 120 & 52.2 & 116 & 50.4 & 1 & 0.669 & GG & Low & $64(27.8)$ & $90(39.1)$ & 1 & \\
\hline $\mathrm{High}(\geq 0.6)$ & 110 & 478 & 114 & 496 & $091(060-139)$ & 0.009 & & High & $38(16.5)$ & $36(15.7)$ & $1.39(0.7$ & 0.257 \\
\hline & & & & & $0.91(0.00-1.39)$ & & GA & Low & $66(28.7)$ & $73(31.7)$ & $1.25(0.77-2.04)$ & 0.366 \\
\hline Spicy food (level) & & & & & & & & High & 35 (15.2) & $24(10.4)$ & $1.99(1.07-3.68)$ & 0.029 \\
\hline Non or less spic & y 31 & 13.7 & 37 & 16.2 & 1 & 0.313 & AA & Low & $19(8.3)$ & $5(2.2)$ & $5.10(1.79-14.5)$ & 0.002 \\
\hline Medium spicy & 106 & 46.7 & 116 & 50.6 & $1.16(0.64-2.1)$ & & & High & $8(3.5)$ & $2(0.9)$ & $6.18(1.22-31.4)$ & 0.028 \\
\hline Very spicy & 90 & 39.6 & 76 & 33.2 & $1.1 .52(0.81-2.84)$ & & $X R C C 1$ & Poultry (averag & ge times/day) & & & 0.0004 \\
\hline Vegetable oil (freq & uency & & & & & & GG & Low & $80(34.8)$ & $111(48.3)$ & 1 & \\
\hline Never & 6 & 2.6 & 13 & 5.7 & 1 & 0.147 & & High & $22(9.6)$ & $15(6.5)$ & $1.81(0.91-3.61)$ & 0.093 \\
\hline Sometime & 7 & 3 & 10 & 43 & 1 & & GA & Low & $79(34.3)$ & $83(36.1)$ & $1.31(0.86-1.99)$ & 0.216 \\
\hline & & 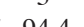 & 10 & 4.3 & $1.35(0.30-4.93$ & & & High & $22(9.6)$ & $14(6.1)$ & $2.01(0.98-4.12)$ & 0.057 \\
\hline Always & 217 & 94.4 & 207 & 90 & $2.39(0.89-6.46)$ & & $\mathrm{AA}$ & Low & $20(8.7)$ & $7(3)$ & $3.75(1.45-9.71)$ & 0.006 \\
\hline Pork oil (frequency & & & & & & & & High & $7(3)$ & 0 & & \\
\hline Never & 196 & 85.2 & 201 & 87.8 & 1 & 0.539 & $X R C C 1$ & Fish (average $t$ & times/day) & & & 0.004 \\
\hline Sometime & 5 & 2.2 & 6 & 2.6 & $0.83(0.25-2.73)$ & & GG & Low & $98(42.6)$ & $117(50.9)$ & 1 & \\
\hline Always & 29 & 12.6 & 22 & 9.6 & $1.39(0.76-2.55)$ & & & High & $4(1.7)$ & $9(3.9)$ & $0.52(0.15-1.73)$ & 0.283 \\
\hline Coconut milk (frec & uenci & & & & & & GA & Low & $91(39.6)$ & $89(38.7)$ & $1.22(0.81-1.83$ & 0.343 \\
\hline Never & 62 & & & & 1 & & & High & $10(4.4)$ & $8(3.5)$ & $1.33(0.51-3.51)$ & 0.559 \\
\hline Sometim & 62 & 26.9 & 61 & 26 & 1 & & AA & Low & $23(10)$ & $5(2.1)$ & $6.11(2.06-18.1)$ & 0.001 \\
\hline Sometime & 97 & 42.2 & 116 & 50.4 & 0.82( & & & High & $4(1.7)$ & $2(0.9)$ & $2.21(0.39-12.2)$ & 0.364 \\
\hline
\end{tabular}

Table 3. Interaction between $X R C C 1$ G399A and Others Environmental Factors 
XRCC1 Polymorphism, Diet and Risk of Colorectal Cancer in Thailand

Table 3 (continued). Interaction between $X R C C 1$ G399A and Others Environmental Factors

\begin{tabular}{clllll}
\hline \multicolumn{7}{c}{ Variables } & \multicolumn{1}{c}{ Case } \\
$\mathrm{n}(\%)$ & $\begin{array}{c}\text { Control } \\
\mathrm{n}(\%)\end{array}$ & OR (95\%CI) & p-value \\
\hline XRCC1 & \multicolumn{7}{c}{ Vegetables (average times/day) } \\
GG & Low & $59(25.6)$ & $64(27.8)$ & 1 & 0.006 \\
& High & $43(18.7)$ & $62(27)$ & $0.80(0.47-1.37)$ & 0.417 \\
GA & Low & $59(25.6)$ & $58(25.2)$ & $1.21(0.72-2.03$ & 0.464 \\
& High & $42(18.3)$ & $39(17)$ & $1.14(0.65-1.99)$ & 0.649 \\
AA & Low & $11(4.8)$ & $4(1.7)$ & $3.52(0.93-13.4)$ & 0.065 \\
& High & $16(7)$ & $3(1.3)$ & $5.31(1.46-19.3)$ & 0.011 \\
XRCC1 & Fruits (average times/day) & & 0.007 \\
GG & Low & $56(24.4)$ & $69(30)$ & 1 & 0.94 \\
& High & $46(20)$ & $57(24.8)$ & $0.98(0.55-1.73)$ & 0.94 \\
GA & Low & $55(23.9)$ & $45(19.5)$ & $1.72(0.97-3.06)$ & 0.064 \\
& High & $46(20)$ & $52(22.6)$ & $1.04(0.60-1.80)$ & 0.887 \\
AA & Low & $9(3.9)$ & $2(0.9)$ & $5.30(1.09-25.6)$ & 0.038 \\
& High & $18(7.8)$ & $5(2.2)$ & $5.09(1.60-16.1)$ & 0.006 \\
\hline
\end{tabular}

consumption $(\mathrm{OR}=3.72$; 95\%CI: $1.43-9.69$, and $\mathrm{OR}=1.99$; 95\% CI: 1.07-3.68, respectively).

Table 4 shows the adjusted ORs and 95\%CIs from the multivariate analysis. A family history of cancer remained as a statistically significant risk factor for $\mathrm{CRC}$ in the multivariate analysis $(\mathrm{OR}=1.80 ; 95 \% \mathrm{CI}: 1.18-2.74)$ as did the XRCC1 AA homozygote (OR=4.96; 95\%CI: 1.90 12.95). None of the dietary intake variables, including the frequency of pork consumption, were significantly related to the risk of CRC.

\section{Discussion}

The objective of this study was to investigate risk factors for colorectal cancer in a population of Northeast Thailand in terms of gene polymorphisms, lifestyle, and dietary habits. This is the first analytic study to include features of $X R C C 1$ gene polymorphisms as possible risk factors in a population of Thailand, which is a low-risk area for colorectal cancer.

The prevalence of the A allele at codon 399 of XRCC1 in the control group (45\%) was consistent with other studies in Thailand (42-59\%) (Kietthubthew et al., 2006; Sangrajrang et al., 2008; Settheetham-Ishida et al., 2011), $X R C C 1$ and its polymorphisms have been studied as potential risk factors for various cancers (Kietthubthew et al., 2006; Kabzinski et al., 2010; Khan et al., 2013; Yi et al., 2013; Zhang et al., 2014), including CRC (Wang et al., 2010; Yin et al., 2012; Zhao et al., 2012). Our present study found no association between the XRCC1 gene heterozygous polymorphism (G399A) and the risk of colorectal cancer. This is consistent with the negative findings of the cohort study of a Singapore Chinese population (Stern et al., 2007) and previous case-control studies (Brevik et al., 2010; Kabzinski et al., 2010; Engin et al., 2011; Gsur et al., 2011; Yin et al., 2012; Przybylowska et al., 2013). The negative finding has also been confirmed in several meta-analyses (Jiang et al., 2010; Liu et al., 2013; Yi et al., 2013). The positive finding that the XRCC1 homozygous A allele was associated with a higher risk of CRC is also consistent with previous case-control studies (Brevik et al., 2010; Kabzinski et al., 2010; Engin et al., 2011; Gsur et al., 2011; Przybylowska et al., 2013).

The finding of an association between a family history of cancer in first degree relatives and the risk of CRC confirms those of our previous case-control studies in Thailand (Sriamporn et al., 2007; Promthet et al., 2010). The finding is also consistent with a case-control study in South-east Siberia (Zhivotovskiy et al., 2012), a report that a first degree family history of CRC in those undergoing colonoscopy was associated with the finding of pathologically significant lesions (Castiglione et al., 2012) and the outcome of a study involving a network of 13 case-control studies conducted across various parts of Italy and Switzerland (Turati et al., 2013). With regard to diet, the present study found no statistically significant associations between various dietary intakes and the risk of CRC. Although the consumption of beef and pork appeared to increase the risk for CRC, the relationships were not statistically significant.

However, these non-significant apparent relationships were inconsistent with the positive findings of one of our previous case-control studies, which reported that meat (beef and/or pork) intake was associated with an increased risk for CRC (Sriamporn et al., 2007). This non-significant result is also inconsistent with the positive findings of a case-control study in Uruguay, a country which leads the world in the production of beef. The study reported that a meat-based dietary pattern, which was rich in saturated fat, animal protein, cholesterol, phosphorus and nutrients originating in red meat, was associated with an increased

Table 4. Multivariates Analyses of Potential Risk Factors

\begin{tabular}{|c|c|c|c|c|c|c|c|c|}
\hline \multirow[t]{2}{*}{ Variables } & & \multicolumn{2}{|c|}{ Cases } & \multicolumn{2}{|c|}{ Controls } & \multirow{2}{*}{$\begin{array}{l}\text { Crude OR } \\
(95 \% \mathrm{CI})\end{array}$} & \multirow{2}{*}{$\begin{array}{l}\text { Adjusted OR } \\
(95 \% \mathrm{CI})\end{array}$} & \multirow[t]{2}{*}{ p-value } \\
\hline & & $\mathrm{n}$ & $\%$ & $\mathrm{n}$ & $\%$ & & & \\
\hline \multirow[t]{3}{*}{ XRCC1 G399A } & GG & 102 & 44.4 & 126 & 54.8 & 1 & 1 & 0.0012 \\
\hline & GA & 101 & 43.9 & 97 & 42.2 & $1.29(0.89-1.89)$ & $1.28(0.86-1.90)$ & \\
\hline & AA & 27 & 11.7 & 7 & 3 & $4.95(1.99-12.3)$ & $4.96(1.90-12.95)$ & \\
\hline \multirow{2}{*}{ Family history of cancer } & No & 144 & 62.6 & 172 & 75.1 & 1 & & 0.007 \\
\hline & Yes & 86 & 37.4 & 57 & 24.9 & $1.74(1.18-2.58)$ & $1.80(1.18-2.74)$ & \\
\hline \multirow[t]{2}{*}{ Beef (average times/day) } & Low $(\leq 0.03)$ & 123 & 53.5 & 132 & 57.4 & 1 & & 0.11 \\
\hline & High $(>0.03)$ & 107 & 46.5 & 98 & 42.6 & $1.5(1.02-2.20)$ & $1.42(0.92-2.19)$ & \\
\hline \multirow[t]{2}{*}{ Pork (average times/day) } & Low $(\leq 0.5)$ & 146 & 64.3 & 168 & 73 & 1 & & 0.173 \\
\hline & High $(>0.5)$ & 81 & 35.7 & 62 & 27 & $1.49(1.00-2.21)$ & $1.35(0.87-2.09)$ & \\
\hline \multirow[t]{2}{*}{ Poultry (average times/day) } & Low $(\leq 0.2)$ & 149 & 64.8 & 168 & 73 & 1 & 1 & 0.059 \\
\hline & $\operatorname{High}(>0.2)$ & 81 & 35.2 & 62 & 27 & $1.45(0.98-2.15)$ & $1.67(0.97-2.86)$ & \\
\hline \multirow{2}{*}{ Fruits (average times/day) } & Low $(<0.6)$ & 120 & 52.2 & 116 & 50.4 & 1 & & 0.228 \\
\hline & High $(\geq 0.6)$ & 110 & 47.8 & 114 & 49.6 & $0.91(0.60-1.39)$ & $0.75(0.47-1.20)$ & \\
\hline
\end{tabular}


risk of CRC whereas a carbohydrate pattern was not, and a plant-based pattern was protective (De Stefani et al., 2012). Similarly, case-control studies in Jordan and India also support a positive connection between red meat consumption and CRC (Ganesh et al, 2009; Arafa et al, 2011).

A large prospective study conducted across 10 European countries found that the consumption of red and processed meat was associated with an increased risk of CRC, but red meat on its own was not related (Norat et al., 2005). A nested case-control prospective study from the Netherlands found that red meat intake increased the risk of CRC in men, but not in women (Tiemersma et al., 2002). However, in cohort studies involving only male subjects a study of white males in the USA (Hsing et al., 1998) was unable to show any statistically significant association between red meat intake and the risk of CRC, and a Finnish study (Pietinen et al., 1999) found that the consumption of meat or processed meat was not associated with an increased risk of CRC. Many meta-analysis studies have confirmed this association between $\mathrm{CRC}$ and meat intake (Sandhu et al., 2001; Norat et al., 2002; Larsson and Wolk, 2006; Sadri and Mahjub, 2006; Huxley et al., 2009; Alexander et al., 2010; Alexander et al., 2011; Chan et al., 2011; Magalhaes et al., 2012).

Regarding the role of fish, the large cohort study conducted in 10 European countries (Norat et al., 2005) found that the consumption of fish was inversely associated with the risk of CRC. This finding was confirmed in a subsequent meta-analysis (Wu et al., 2012), but the outcome of a multicentre controlled trial in the Netherlands and the UK suggests that fish consumption does not markedly change apoptotic and mitotic rates in the colonic mucosa. For poultry, our results suggested a positive relationship between intake and the risk of CRC, but this finding failed to reach statistical significance. In the large European cohort study, poultry consumption was shown to be unrelated to CRC (Norat et al., 2005). In terms of the consumption of fruits and vegetables, the current study found no statistically significant associations with CRC, although both appeared to be protective factors. The lack of a relationship between CRC and fruit and vegetable intakes was confirmed in the Finnish study (Pietinen et al., 1999), but total fruit and vegetable consumption and especially fruit intake were found to be protective factors in a Swedish cohort of women receiving mammography screening (Terry et al., 2001).

Regarding alcohol, the results of present study are consistent with those of our previous study (Sriamporn et al., 2007) which found no relationship between alcohol use and CRC in a multivariate analysis. However, in the Siberian case-control study mentioned earlier (Zhivotovskiy et al., 2012) the use of alcohol in general and, more specifically, the drinking of beer and hard liquor were all strong risk factors for CRC. Interestingly, the consumption of wine was not associated with an increased risk, and the drinking of at least one glass per week appeared to be a protective factor.

Our present study found no association between smoking and CRC risk. Similarly, no statistically significant relationship was found in the US cohort study of white males (Hsing et al., 1998). However, a smoking history of more than 15 years duration was associated with increased risk in the Netherlands cohort study (Tiemersma et al., 2002) A positive association between smoking and the elevated risk of CRC was also confirmed by the large cohort study of 10 European countries (Leufkens et al., 2011), by the Netherlands cohort study (Tiemersma et al., 2002), by the Siberian case-control study (Zhivotovskiy et al., 2012), and in a meta-analysis (Huxley et al., 2009).

One important limitation of this study is the potential for recall bias. This problem is a frequently mentioned problem in case-control studies and arises here because colorectal cancer cases may tend to recall factors related to their disease better than controls, especially factors about life style or behavioral factors. However, for genetic factors, this bias cannot happen since there are no changes in the genotype after conception.

In conclusion, while the XRCC1 AA homozygote and a family history of cancer were found to be associated with an increased risk of CRC, none of the dietary intake variables were clearly identified as risk or protective factors. However, there appears to be a considerable degree of inconsistency between the findings of previously reported studies regarding dietary risk factors for CRC, and there is a need for further research to determine the reasons for this.

\section{Acknowledgements}

The authors would like to acknowledge the financial support of a Royal Golden Jubilee Ph.D. Program Scholarship for Kirati Poomphakwaen and Professor Supannee Promthet (Grant No. PHD/0102/2553) from the Thailand Research Fund, Khon Kaen University, and the National Research Council of Thailand. Thanks are also due to MONKASHO (The Japanese Ministry of Education, Culture, Sports, Science, and Technology) for its initial support at the first phase of the project. Finally, we wish to acknowledge Professor Tokudome for initiating the International collaborative epidemiological study, and Peter Bradshaw for his advice and assistance in writing this paper.

\section{References}

Alexander DD, Miller AJ, Cushing CA, Lowe KA (2010). Processed meat and colorectal cancer: a quantitative review of prospective epidemiologic studies. Eur J Cancer Prev, 19, 328-41.

Alexander DD, Weed DL, Cushing CA, Lowe KA (2011). Metaanalysis of prospective studies of red meat consumption and colorectal cancer. Eur J Cancer Prev, 20, 293-307.

Arafa MA, Waly MI, Jriesat S, Al Khafajei A, Sallam S (2011). Dietary and lifestyle characteristics of colorectal cancer in Jordan: a case-control study. Asian Pac J Cancer Prev, 12, 1931-6.

Bravi F, Edefonti V, Bosetti C, et al (2010). Nutrient dietary patterns and the risk of colorectal cancer: a case-control study from Italy. Cancer Causes Control, 21, 1911-8.

Brevik A, Joshi A D, Corral R, et al (2010). Polymorphisms in base excision repair genes as colorectal cancer risk factors and modifiers of the effect of diets high in red meat. Cancer 
Epidemiol Biomarkers Prev, 19, 3167-73.

Castiglione G, Visioli CB, Zappa M, et al (2012). Familial risk of colorectal cancer in subjects attending an organised screening programme. Dig Liver Dis, 44, 80-3.

Chan DS M, Lau R, Aune D, et al (2011). Red and processed meat and colorectal cancer incidence: meta-analysis of prospective studies. PloS One, 6, 20456.

De Stefani E, Ronco AL, Boffetta P, et al (2012). Nutrientderived dietary patterns and risk of colorectal cancer: a factor analysis in Uruguay. Asian Pac J Cancer Prev, 13, 231-5.

Durko L, Malecka-Panas E (2014). Lifestyle modifications and colorectal cancer. Curr Colorectal Cancer Rep, 10, 45-54.

Engin AB, Karahalil B, Karakaya AE, Engin A (2011). Association between XRCC1 ARG399GLN and P53 ARG72PRO polymorphisms and the risk of gastric and colorectal cancer in Turkish population. Arh Hig Rada Toksikol, 62, 207-14.

Ferlay J, Soerjomataram I, Ervik M, et al (2013). GLOBOCAN 2012 v1.0, Cancer Incidence and Mortality Worldwide: IARC CancerBase No.11. International Agency for Research on Cancer. internet. Retrieved May 13, 2014, from http:// globocan.iarc.fr

Ganesh B, Talole SD, Dikshit R (2009). A case-control study on diet and colorectal cancer from Mumbai, India. Cancer Epidemiol, 33, 189-93.

Gsur A, Bernhart K, Baierl A, et al (2011). No association of XRCC1 polymorphisms Arg194Trp and Arg399Gln with colorectal cancer risk. Cancer Epidemiol, 35, 38-41.

Hong YC, Lee KH, Kim WC, et al (2005). Polymorphisms of $X R C C 1$ gene, alcohol consumption and colorectal cancer. Int J Cancer, 116, 428-32.

Hsing AW, McLaughlin JK, Chow WH, et al (1998). Risk factors for colorectal cancer in a prospective study among U.S. white men. Int J Cancer, 77, 549-53.

Huxley RR, Ansary-Moghaddam A, Clifton P, et al (2009). The impact of dietary and lifestyle risk factors on risk of colorectal cancer: A quantitative overview of the epidemiological evidence. Int J Cancer, 125, 171-80.

Jiang Z, Li C, Xu Y, Cai S (2010). A meta-analysis on XRCC1 and XRCC3 polymorphisms and colorectal cancer risk. Int J Colorectal Dis, 25, 169-80.

Kabzinski J, Przybyłowska K, Mik M, et al (2010). An association of ARG399GLN polymorphism of XRCC1 gene with a risk of colorectal cancer. Polish J Surg, 82, 677-80.

Khan NP, Pandith AA, Yousuf A, et al (2013). The XRCC1 Arg399Gln gene polymorphism and risk of colorectal cancer: A study in Kashmir. Asian Pac J Cancer Prev, 14, 6779-82.

Kietthubthew S, Sriplung H, Au WW, Ishida T (2006). Polymorphism in DNA repair genes and oral squamous cell carcinoma in Thailand. Int J Hyg Environ Health, 209, 21-9.

Larsson SC, Wolk A (2006). Meat consumption and risk of colorectal cancer: a meta-analysis of prospective studies. Int J Cancer, 119, 2657-64.

Leufkens AM, Van Duijnhoven FJ, Siersema PD, et al (2011). Cigarette smoking and colorectal cancer risk in the European Prospective Investigation into Cancer and Nutrition study. Clin Gastroenterol Hepatol, 9, 137-44.

Liu L, Miao L, Ji G, et al (2013). Association between XRCC1 and XRCC3 polymorphisms and colorectal cancer risk: A meta-analysis of 23 case-control studies. Mol Biol Rep, $\mathbf{4 0 ,}$ 3943-52.

Magalhaes B, Peleteiro B, Lunet N (2012). Dietary patterns and colorectal cancer: systematic review and meta-analysis. Eur J Cancer Prev, 21, 15-23.

Makambi KH, Agurs-Collins T, Bright-Gbebry M, et al (2011). Dietary patterns and the risk of colorectal adenomas: the Black Women's Health Study. Cancer Epidemiol Biomarkers
Prev, 20, 818-25.

Navarro A (2005). Food culture may be a risk factor for colorectal cancer among Argentineans: the human history of this research. Nutrition, 21, 1164-6.

Nayak SP, Sasi MP, Sreejayan MP, Mandal S (2009). A casecontrol study of roles of diet in colorectal carcinoma in a South Indian Population. Asian Pac J Cancer Prev, 10, 565-8.

Nissar S, Lone TA, Banday MZ, et al (2013). Arg399Gln polymorphism of $\mathrm{XRCC} 1$ gene and risk of colorectal cancer in Kashmir: A case control study. Oncol Lett, 5, 959-63.

Norat T, Bingham S, Ferrari P, et al (2005). Meat, fish, and colorectal cancer risk: The European Prospective Investigation into Cancer and Nutrition. J Natl Cancer Inst, 97, 906-16.

Norat T, Lukanova A, Ferrari P, Riboli E (2002). Meat consumption and colorectal cancer risk: dose-response metaanalysis of epidemiological studies. Int J Cancer, 98, 241-56.

Pietinen P, Malila N, Virtanen M, et al (1999). Diet and risk of colorectal cancer in a cohort of Finnish men. Cancer Causes Control, 10, 387-96.

Pot GK, Majsak-Newman G, Geelen A, et al (2009). Fish consumption and markers of colorectal cancer risk: a multicenter randomized controlled trial. Am J Clin Nutr, 90, 354-61.

Promthet S, Pientong C, Ekalaksananan T, et al (2012). Risk factors for rectal cancer and methylenetetrahydrofolate reductase polymorphisms in a population in Northeast Thailand. Asian Pac J Cancer Prev, 13, 4017-23.

Promthet SS, Pientong C, Ekalaksananan T, et al (2010). Risk factors for colon cancer in Northeastern Thailand: interaction of MTHFR codon 677 and 1298 genotypes with environmental factors. J Epidemiol, 20, 329-38.

Przybylowska K, Kabzinski J, Sygut A, et al (2013). An association selected polymorphisms of $X R C C 1$, OGG1 and MUTYH gene and the level of efficiency oxidative DNA damage repair with a risk of colorectal cancer. Mutat Res, 745-6, 6-15.

Randi G, Edefonti V, Ferraroni M, et al (2010). Dietary patterns and the risk of colorectal cancer and adenomas. Nutr Rev, 68, 389-408.

Rossit AR, Cabral IR, Hackel C, et al (2002). Polymorphisms in the DNA repair gene $X R C C 1$ and susceptibility to alcoholic liver cirrhosis in older Southeastern Brazilians. Cancer Lett, 180, 173-82.

Sadri GH, Mahjub H (2006). Meat consumption is a risk factor for colorectal cancer: meta-analysis of case-control studies. Pakistan J Nutrition, 5, 230-3.

Sandhu MS, White IR, McPherson K (2001). Systematic review of the prospective cohort studies on meat consumption and colorectal cancer risk a meta-analytical approach. Cancer Epidemiol Biomarkers Prev, 10, 439-46.

Sangrajrang S, Schmezer P, Burkholder I, et al (2008). Polymorphisms in three base excision repair genes and breast cancer risk in Thai women. Breast Cancer Res Treat, 111, 279-88.

Settheetham-Ishida W, Yuenyao P, Natphopsuk S, et al (2011). Genetic risk of DNA repair gene polymorphisms (XRCC1 and XRCC3) for high risk human papillomavirus negative cervical cancer in Northeast Thailand. Asian Pac J Cancer Prev, 12, 963-6.

Sriamporn S, Wiangnon S, Suwanrungruang K, et al (2007). Risk factors for colorectal cancer in northeast Thailand: lifestyle related. Asian Pac J Cancer Prev, 8, 573-7.

Stefani ED, Deneo-Pellegrini H, Ronco AL, et al (2011). Dietary patterns and risk of colorectal cancer: a factor analysis in Uruguay. Asian Pac J Cancer Prev, 12, 753-9. 
Kirati Poomphakwaen et al

Stern MC, Conti DV, Siegmund KD, et al (2007). DNA repair single-nucleotide polymorphisms in colorectal cancer and their role as modifiers of the effect of cigarette smoking and alcohol in the Singapore Chinese Health Study. Cancer Epidemiol Biomarkers Prev, 16, 2363-72.

Sung JJ, Lau JY, Goh K L, Leung WK: Asia Pacific Working Group on Colorectal Cancer (2005). Increasing incidence of colorectal cancer in Asia: implications for screening. Lancet Oncol, 6, 871-6.

Terry P, Giovannucci E, Michels KB, et al (2001). Fruit, Vegetables, Dietary Fiber, and Risk of Colorectal Cancer. $J$ Natl Cancer Inst, 93, 525-33.

Thacker J, Zdzienicka MZ (2004). The XRCC genes: Expanding roles in DNA double-strand break repair. DNA Repair, $\mathbf{3}$, 1081-90.

Tiemersma EW, Kampman E, Bueno de Mesquita HB, et al (2002). Meat consumption, cigarette smoking, and genetic susceptibility in the etiology of colorectal cancer: results from a Dutch prospective study. Cancer Causes Control, 13, 383-93.

Turati F, Edefonti V, Bosetti C, et al (2013). Family history of cancer and the risk of cancer: A network of case-control studies. Ann Oncol, 24, 2651-6.

Wang J, Zhao Y, Jiang J, et al (2010). Polymorphisms in DNA repair genes XRCC1, XRCC3 and XPD, and colorectal cancer risk: A case-control study in an Indian population. $J$ Cancer Res Clin Oncol, 136, 1517-25.

Wu S, Feng B, Li K, et al (2012). Fish consumption and colorectal cancer risk in humans: a systematic review and meta-analysis. Am J Med, 125, 551-9.

Yee YK, Tan VP, Chan P, et al (2009). Epidemiology of colorectal cancer in Asia. J Gastroenterol Hepatol, 24, 1810-6.

Yi L, Xiao-feng H, Yun-tao L, et al (2013). Association between the XRCC1 Arg399Gln polymorphism and risk of cancer: evidence from 297 case-control studies. PLoS ONE, 8, 78071.

Yin G, Morita M, Ohnaka K, et al (2012). Genetic polymorphisms of XRCC1, alcohol consumption, and the risk of colorectal cancer in Japan. $J$ Epidemiol, 22, 64-71.

Zhang XL, Lu Y, Yang S, et al (2014). An updated metaanalysis between the association of XRCC1 Arg399Gln polymorphism and hepatocellular carcinoma risk. Asian Pac J Cancer Prev, 15, 3273-8.

Zhao Y, Deng X, Wang Z, et al (2012). Genetic polymorphisms of DNA repair genes XRCC1 and XRCC3 and risk of colorectal cancer in Chinese population. Asian Pac J Cancer Prev, 13, 665-9.

Zhivotovskiy AS, Kutikhin AG, Azanov AZ, et al (2012). Colorectal cancer risk factors among the population of south-east Siberia: A case-control study. Asian Pac J Cancer Prev, 13, 5183-8. 